\title{
Normal pressure hydrocephalus: a qualitative study on outcome
}

\author{
Hidrocefalia de pressão normal: história natural e prognóstico após cirurgia
}

Paulo Bugalho',2, Luísa Alves ${ }^{1,2}$, Olga Ribeiro'

\begin{abstract}
Objective: To describe the natural history and shunt outcome in patients with normal pressure hydrocephalus (NPH) and the variables that influence both. Method: Motor and cognitive parameters of 35 patients with NPH, as well as shunt surgery status, were registered at two time points (TO and T1). Results: Thirteen patients underwent shunt surgery. Favorable outcome in gait function occurred in 5 of 35 patients and was related to younger age, absence of cardiovascular risk factors (CVRF) and white matter lesions (WML), and shunt surgery. Cognitive outcome was favorable in 9 of 35 patients and associated with shunt surgery (trend level). Of the patients subjected to surgery, favorable outcome in motor function was related to younger age at T0 and absence of CVRF and WML (trend level). Conclusion: Shunt surgery had a significant effect on gait and less on cognition. Favorable outcome in gait was also associated with younger age and absence of CVRF and WML.
\end{abstract}

Keywords: normal pressure hydrocephalus, natural history, shunt surgery.

\section{RESUMO:}

Objetivo: Descrever a história natural e o prognóstico após cirurgia de derivação ventricular em doentes com hidrocefalia de pressão normal (HPN), e as variáveis que potencialmente os influenciam. Método: Foram registados os parâmetros motores e cognitivos de 35 doentes com HPN, assim como o status relativo a cirurgia, em dois pontos no tempo (T0 e T1). Resultados: Treze doentes foram submetidos a cirurgia. Melhoria na marcha ocorreu em 5 doentes e relacionou-se com idade mais jovem, ausência de factores de risco cardio-vascular (FRCV), ausência de lesões da substância branca (LSB) e colocação de derivação ventricular. Verificou-se melhoria cognitiva em 9 doentes, associada $(p=0,05)$ com colocação de derivação ventricular. Em doentes submetidos a cirurgia, o prognóstico favorável a nível motor relacionou-se com idade mais jovem em TO, ausência de FRCV e de LSB. Conclusão: A cirurgia para colocação de derivação ventricular teve um efeito significativo sobre a marcha e menor na cognição. O prognóstico favorável na marcha parece também associar-se a idade mais jovem, a ausência de FRV e de LSB.

Palavras-chave: hidrocefalia de pressão normal, história natural, cirurgia de derivação ventriculo-peritoneal.

Normal pressure hydrocephalus (NPH) was first described by Hakim and Adams as a syndrome that consisted of the triad of gait dysfunction, dementia, and urinary incontinence, was associated with ventricular dilation, was potentially treatable by cerebrospinal fluid (CSF) surgical derivation (shunt surgery) ${ }^{1}$. Enthusiasm for shunt surgery decreased, however, as further studies revealed complications of the surgical procedure and lack of improvement in many cases. This prompted an extensive search for tests that could predict response to shunt surgery and for clinical and imagiological prognostic factors. Some authors have differentiated between the prognostic and diagnostic value of ancillary tests, proposing that diagnosis should be based solely on clinical criteria (negative response to shunt surgery or negative results in tests that predict shunt response should not exclude NPH diagnosis, as brain changes in many patients may already be irreversible) $)^{2}$. Investigative approaches have varied from clinically based studies ${ }^{3}$ to technically demanding procedures such as intracranial pressure (ICP) monitoring and determination of CSF outflow resistance (CSFRo). Results assessing the ability of the CSFRo value to predict response to shunt surgery have varied from study to study, and thresholds seem to depend on the protocol used by each center ${ }^{4,5}$. ICP monitoring and CSFRo are also time and money consuming and more invasive than other procedures. Measures of outcome after shunt surgery have also varied widely from study

\footnotetext{
${ }^{1}$ Neurology Department, Hospital de Egas Moniz (CHLO), Centro de Estudos de Doenças Crónicas (CEDOC), NOVA Medical School, Universidade Nova de Lisboa, Lisboa, Portugal;

${ }^{2}$ Neurology Department, Faculdade de Ciências Médicas da Universidade Nova de Lisboa, Centro de Estudos de Doenças Crónicas (CEDOC), NOVA Medical School, Universidade Nova de Lisboa, Lisboa, Portugal.

Correspondence: Paulo Bugalho; Neurology Department; Hospital de Egas Moniz (CHLO); Rua da Junqueira 126; $1349-019$ Lisboa - Portugal; E-mail: paulobugalho@sapo.pt Conflict of interest: There is no conflict of interest to declare.
}

Received 04 November 2012; Received in final form 21 June 2013; Accepted 28 June 2013. 
to study; these include semi-quantitative global scales and more specific measures of cognitive and gait dysfunction, which are seldom accessible in most clinical environments, leading some to defend more clinically driven bedside approaches, particularly in relation to gait ${ }^{6}$. The natural history of NPH is relatively unexplored because investigations have mainly been driven by the need to find suitable candidates for shunt surgery. Information about the natural history could be valuable for planning the follow-up of patients for whom surgical treatment is not indicated or who refuse intervention when proposed.

In this study, our objectives were to describe the natural history and shunt outcome of a cohort of idiopathic NPH patients, who have been evaluated with accessible clinical and imagiological tools.

\section{METHOD}

\section{Participants}

Inclusion criteria were clinically based and followed proposed guidelines for probable $\mathrm{NPH}^{7}$ : 1. symmetrical, slowly progressive gait dysfunction with insidious onset; 2. at least one other symptom of the triad (urinary incontinence not explained by urologic conditions, cognitive decline); 3. insidious onset of symptoms after 40 years of age; 4 . non-obstructive hydrocephalus (Evan's index $>0.3$ ) with obliteration of the cerebral sulci; 5. normal CSF pressure at lumbar puncture (LP) (70-245 mm H2O); 6. exclusion of other causes.

\section{Description of procedures undertaken}

To guide therapeutic decisions, patients underwent a study protocol designed to predict response to shunt surgery. Decisions were based on the conjoined input of the neurologist, patient, and family members after discussion of the risks and benefits in each individual case. Decisions were thus tailored to each situation and not guided by homogenous guidelines. Some patients did not perform some of the tests (specified below).

\section{Study protocol}

Patient outcome was assessed by cognitive and gait dysfunction at two different time points (T0 and T1). Time between assessments varied from patient to patient, but was always greater than 1 year (range: 1 to 9 years). We also registered the symptoms of the triad, first symptom of the triad, age at study inclusion, age of onset, duration of symptoms, and time from T0 to T1. A mini-Mental State Examination $(\mathrm{MMSE})^{8}$ score at T0 was available for 31 patients (cognitive dysfunction defined according to cut-off scores of the Portuguese version of the test ${ }^{9}$ ).

Thirty-one patients were evaluated by a 10-m timed walking test, with assessment of gait velocity, stride length, and stride duration. Postural responses were tested by a shoulder tug test, which assesses the patient's postural responses to a backward tug on the shoulders ${ }^{10}$. The tests were performed in our department's in-patient clinic in standardized conditions at admission, before and 12, 24, 48, and $72 \mathrm{~h}$ after high volume ( $40 \mathrm{ml}$ ) LP. Variation percentages were calculated for each of the four variables, according to the following formula: [(result before LP-best result after LP)/result before LP] $\times$ 100. We defined clinical improvement as amelioration of at least $20 \%$ of at least one gait variable after LP. Patients were assessed for the presence of frontal and subcortical hypokinetic gait clinical features, according to definitions provided by Jankovic et al. ${ }^{11}$ : slowness, abnormal postural adjustments, freezing, abnormal stance, disequilibrium, stiff trunk/legs, leg apraxia, improvement with cues, frontal signs, short stride, shuffling, narrow base, festination, start hesitation, turn en bloc, and Parkinsonian signs.

All patients underwent brain MRI to confirm imagiological criteria for NPH and to evaluate the presence of white matter ischemic lesions (WML). For subsequent analysis of WML, patients were classified according to the presence or absence of at least 1 lesion, irrespective of the region(s) affected. The MRI study was accompanied by the determination of CSF stroke volume in 20 patients. Values above $42 \mu \mathrm{l}$ were considered to predict a favorable outcome ${ }^{12}$. Cerebrovascular risk factors (CVRF) were registered and defined as follows: 1. arterial hypertension: documented history or treatment for hypertension, or blood pressure above $150 \mathrm{mmHg}$ systolic or $90 \mathrm{mmHg}$ diastolic on at least two occasions; 2. diabetes mellitus: documented history or treatment for diabetes mellitus or fasting glucose levels above $5.2 \mathrm{mmol} / \mathrm{L} ; 3$. hyperlipidemia: fasting triglyceride level above $1.6 \mathrm{mmol} / \mathrm{L}$ and/or fasting total cholesterol level above $200 \mathrm{mg} / \mathrm{dL} ; 4$. smoking habits: past or present use of tobacco; 5 . cardiac diseases: documented history or treatment for cardiac disorders such as ischemic heart disease, cardiac insufficiency, or atrial fibrillation; 6. previous stroke: documented history or treatment for transient ischemic attack or stroke; 7. peripheral atherosclerosis: documented history of renal, aortic, iliac, limb, or retinal atherosclerosis.

A qualitative grading of cognitive and gait dysfunction was performed at $\mathrm{T} 0$ and $\mathrm{T} 1$.

Gait: 1. Normal; 2. Gait dysfunction as perceived by the patient, the clinician, or caretaker, but autonomous (no need for walking aid or help from another person); 3 . Need of walking aid; 4. Bedridden.

Cognition: 1. Normal; 2. Cognitive dysfunction as perceived by the patient, the clinician, or caretaker, but without criteria for dementia (according to the DSM-IV definition); 3. Dementia according to the DSM-IV definition ${ }^{13}$.

Patients were considered to have a favorable (as opposed to an unfavorable) outcome at $\mathrm{T} 1$ if they maintained normal status or improved dysfunctional status. 


\section{Ethics}

All patients signed informed consent forms, allowing the use of clinical data for scientific purposes. This study was approved by the local ethics committee (Comissão de Ética do Centro Hospitalar de Lisboa Ocidental).

\section{Statistical methods}

For statistical purposes, continuous variables were dichotomized. The relationship between cognitive and gait status at follow-up and each variable at T0 was studied by chisquare statistics, both globally and separately according to treatment (shunt Vs non-shunt).

\section{RESULTS}

We studied 35 patients, of which 21 were male. Mean age at T0 was $74.5 \pm 6.29$ years. Age of onset was $71.7 \pm 6.86$ years. Time from T0 to T1 was $3.1 \pm 1.96$ years (range, $1-9$ ). Symptoms at T0 were gait (11), gait and cognition (6), gait and urinary incontinence (4), all (14). First symptom was gait (23), cognition (3), more than one symptom simultaneously (9). Gait at T0/T1 was graded as follows: normal function, 2/5; dysfunction but autonomous, 18/7; need of walking aid, 11/17; bedridden, 3/6. Cognition at T0/T1 was graded as follows: normal, 11/7; dysfunction, 12/11; dementia, $11 / 17$.

Of the 35 patients examined, 13 received shunt surgery (which took place after $\mathrm{T} 0$ and before $\mathrm{T} 1$ ). Ten received a ventriculo-peritoneal shunt (7 with flux valves and 3 with programmable valves) and 3 underwent ventriculostomy. Nine additional patients were proposed for surgery but refused. For statistical purposes, patients subjected to the different kinds of surgical procedures were evaluated as a single group.
Positive outcome in cognitive and gait function occurred in 9 and 5 total (surgical and non-surgical) patients, respectively.

Table 1 shows the comparison between patients with favorable and unfavorable gait function outcome. Younger age at onset, younger age at $\mathrm{T} 0$, and shunt surgery were significant factors for patients with favorable outcome. CVRF and WML were significantly more frequent in patients with unfavorable outcome.

Positive outcome in cognition was associated with shunt surgery, but only at trend level (Table 2).

In patients subjected to surgery, favorable outcome in motor function was also related to younger age at $\mathrm{T} 0$ and absence of CVRF. Absence of WML, younger age of onset, shorter duration, and shorter time between assessments were related to favorable outcome in gait disturbance after shunt surgery at trend level $(0.05<p<0.1)$. In this group, cognitive function outcome was not significantly related to any variable (Table 3).

In terms of gait dysfunction, all patients not subjected to shunt surgery worsened or maintained disease status (defined as unfavorable outcome). To better assess the natural history of NPH, we divided this group into those who maintained their previous status, even if not normal, and those with deteriorated motor status at T1. Longer time from T0 to T1 was significantly associated with declining motor status $(p=0.012)$. WML were more frequent in patients who worsened, with a difference that almost reached significance $(p=0.069)$. Cognitive dysfunction as measured by MMSE at $\mathrm{T} 0$ and/or T1 was significantly less frequent in patients who worsened $(p=0.010)$.

Gait features, as defined by Jankovic et al., were not significantly related to gait or cognitive outcome, either globally or in the surgery group (results not shown).

WML, CVRF, and older age were not related to each other, according to chi-square analysis.

Table 1. Gait outcome (global).

\begin{tabular}{|c|c|c|c|}
\hline 35 patients & Favorable $(n=5)$ & Unfavorable $(n=30)$ & $p$-value \\
\hline Age at TO (<70 years) & 5 & 2 & $<0.00001^{* \star * \star *}$ \\
\hline Age of onset ( $<70$ years) & 5 & 7 & $0.002^{* * *}$ \\
\hline T0 to T1 ( $<3$ years) & 4 & 15 & 0.347 \\
\hline Duration ( $<3$ years) & 5 & 19 & 0.157 \\
\hline First symptom (gait Vs cognition) & 3 & 19 & 1.000 \\
\hline Complete triad at TO & 1 & 13 & 0.627 \\
\hline MMSE (normal Vs abnormal) $\left(n=31,4\right.$ Vs 27) ${ }^{a}$ & 3 & 11 & 0.304 \\
\hline CVRF (at least one Vs none) & 1 & 25 & $0.010^{*}$ \\
\hline WML (at least one Vs none) & 0 & 20 & $0.009^{* *}$ \\
\hline Surgery & 5 & 8 & $0.004^{* \star \star}$ \\
\hline Response to LP $(n=31,5$ Vs 26) & 4 & 22 & 1.000 \\
\hline CSF stroke volume $(>42 \mu \mathrm{g})(\mathrm{n}=20,3 \mathrm{Vs} 17)^{\mathrm{a}}$ & 2 & 15 & 0.404 \\
\hline
\end{tabular}

Values represent number of patients. ${ }^{* * * *} p<0.0005 ;{ }^{* * *} p<0.005,{ }^{* *} p<0.01,{ }^{*} p<0.05$. aData for all variables were not available for all patients. Total $n(n=\ldots)$ and number of patients with positive Vs negative outcome (...Vs...) are indicated after each variable. n: number; CVRF: cerebrovascular risk factors; WML: white matter lesions; MMSE: Mini-Mental State Examination; CSF: cerebrospinal fluid; TO and T1: time points at which outcome is assessed. 
Table 2. Cognition outcome (global).

\begin{tabular}{|c|c|c|c|}
\hline 35 patients & $\begin{array}{l}\text { Favorable } \\
\qquad(n=9)\end{array}$ & $\begin{array}{c}\text { Unfavorable } \\
(n=26)\end{array}$ & $p$-value \\
\hline Age $(<70)$ & 4 & 8 & 0.361 \\
\hline Age of onset $(<70)$ & 3 & 4 & 0.340 \\
\hline T0 to T1 $\left(3<V_{s}>2 \mathrm{y}\right)$ & 5 & 14 & 0.619 \\
\hline Duration ( $\langle 5$ Vs $\rangle 4 \mathrm{y})$ & 3 & 17 & 0.129 \\
\hline First symptom (gait Vs cognition) & 8 & 14 & 0.109 \\
\hline Complete triad at TO & 1 & 12 & 0.262 \\
\hline MMSE (normal Vs abnormal) $\left(n=31,4\right.$ Vs 27) ${ }^{a}$ & 2 & 12 & 0.240 \\
\hline CVRF (at least one) & 6 & 20 & 0.665 \\
\hline WML (at least one) & 3 & 17 & 0.129 \\
\hline Surgery & 6 & 7 & 0.050 \\
\hline Response to LP $(n=31,7$ Vs 24) a & 6 & 20 & 1.000 \\
\hline CSF stroke volume $(>42 \mu g)(n=20,5$ Vs 15) & 5 & 12 & 0.539 \\
\hline
\end{tabular}

Values represent number of patients. ${ }^{a}$ Data for all variables were not available for all patients. Total $n(n=)$ and number of patients improved/non-improved (...Vs...) are indicated after of each variable. N: number; CVRF: cerebrovascular risk factors; WML: white matter lesions; MMSE: Mini-Mental State Examination; CSF: cerebrospinal fluid; T0 and T1: time points at which outcome is assessed.

Table 3. Outcome in gait and cognitive dysfunction of patients subjected to shunt surgery ( $n=13)$.

\begin{tabular}{|c|c|c|c|c|c|c|}
\hline 13 patients & $\begin{array}{c}\text { Gait: } \\
\text { favorable } \\
(n=5)\end{array}$ & $\begin{array}{c}\text { Gait: } \\
\text { unfavorable } \\
(n=8)\end{array}$ & $\mathrm{p}$-value & $\begin{array}{l}\text { Cognition: } \\
\text { favorable } \\
(n=6)\end{array}$ & $\begin{array}{l}\text { Cognition: } \\
\text { unfavorable } \\
(n=7)\end{array}$ & $\mathrm{p}$-value \\
\hline Age $(<70)$ & 5 & 1 & $0.005^{* \star}$ & 3 & 3 & 1.000 \\
\hline Age of onset $(<70)$ & 5 & 3 & 0.075 & 3 & 5 & 0.592 \\
\hline T0 to T1 (<3 years) & 5 & 3 & 0.075 & 5 & 3 & 0.256 \\
\hline Duration (<5 years) & 5 & 4 & 0.086 & 6 & 3 & 0.266 \\
\hline First symptom (gait) & 3 & 7 & 0.580 & 6 & 4 & 0.559 \\
\hline Complete triad at TO & 1 & 4 & 0.565 & 2 & 3 & 1.000 \\
\hline MMSE (below cut-off) $(n=12)$ & 3 & 2 & 0.222 & 2 & 3 & 1.000 \\
\hline CVRF (at least one Vs none) & 1 & 7 & $0.032^{*}$ & 3 & 5 & 0.592 \\
\hline WML (at least one Vs none) & 0 & 5 & 0.075 & 1 & 4 & 0.266 \\
\hline Response to LP $(n=12)$ & 4 & 7 & 0.417 & 4 & 7 & 0.417 \\
\hline CSF stroke volume $(n=8)^{a}$ & 2 & 5 & 0.375 & 4 & 3 & 1.000 \\
\hline
\end{tabular}

Values represent number of patients. ${ }^{* *} p<0.01 ;{ }^{*} p<0.05$. ${ }^{\text {a }}$ ata for all variables were not available for all patients. Total $n(n=)$ is indicated after each variable. CVRF: cerebrovascular risk factors; N: number; WML: white matter lesions; MMSE: Mini-Mental State Examination; CSF: cerebrospinal fluid; T0 and T1: time points at which outcome is assessed.

\section{DISCUSSION}

NPH patient outcome was highly variable and differed in respect to cognitive and gait dysfunction.

\section{Factors influencing gait dysfunction outcome}

Patients with favorable gait outcome were all part of the surgical treatment group. Longer time between assessments was associated with increased gait dysfunction of nonoperated patients, which suggests that gait dysfunction is largely an irreversible condition that tends to worsen over time if not treated. Surgical treatment, however, was beneficial for less than half of the patients, emphasizing the need for careful selection. Older age at time of assessment and the presence of CVRF were associated with unfavorable gait outcome for operated patients. The presence of WML was also significantly $(\mathrm{p}<0.05)$ associated with unfavorable outcome globally, and at trend level $(0.05<\mathrm{p}<0.1)$ both on operated and not operated patients. Older age has been reported to be a negative prognostic factor in some ${ }^{14}$, but not all ${ }^{15}$ studies. The relationship between cerebrovascular disease and NPH has also been alluded to in previous work. Bugalho et al. demonstrated an inverse relationship between the presence of WML and gait recovery after LP, suggesting that WML could preclude improvement after shunt surgery ${ }^{16}$. Other studies suggested that WML are factors for worse prognosis after shunt placement ${ }^{17}$. However, some authors have suggested that WML should not contraindicate shunt surgery per se because some patients can benefit even if they have $\mathrm{WML}^{18}$. This premise is not corroborated by our study, in 
which none of the patients with WML had a favorable gait outcome. Our results thus indicate that age and presence of WML and CVRF can predict worse gait outcome and should be weighed as negative factors in decisions regarding surgical treatment.

CVRF, age, and WML were found to be significantly related, particularly in studies performed on leukoaraiosis patients ${ }^{19}$. We found no relation between these variables, either in operated or non-operated patients, which suggests that they independently influence NPH physiopathology by different mechanisms. Old age could associate with other comorbidities, such as cerebral degenerative changes or osteoarticular disease, neither of which would reverse with shunt surgery. Other studies have suggested that while WML can contribute to symptoms by interrupting cognitive and gait pathways, CVRF, and arterial hypertension in particular, could act by increasing CSF pulsatility ${ }^{20}$.

\section{Factors influencing cognitive dysfunction outcome}

Unlike gait outcome, cognitive outcome was not related to any factor except surgical treatment and only at trend level. This discrepancy may reflect the different pathophysiological mechanisms that produce gait and cognitive dysfunction. Also, with regard to the influence of WML, the location of lesions, not assessed in this study, may be more harmful to gait than to cognition. The weaker response of cognitive than of gait dysfunction to shunt therapy, as reported in some papers ${ }^{21,22}$, could be caused by the superimposed effects of degenerative changes on cognition-related structures, such as those of Alzheimer's disease, which have been found in some studies to contribute to NPH cognitive dysfunction and worse shunt outcome $^{23}$. The higher frequency of cognitive dysfunction in patients whose gait did not worsen could also mean that cognitive and motor deterioration take divergent and possibly opposing pathways. Weaker association of cognitive function with shunt surgery could also be related to the presence in our study of non-shunted patients with positive outcome. These patients all maintained normal status, suggesting that progressive cognitive deterioration is not obligatory in NPH.

\section{Factors not found to be related to outcome}

Some factors found by other studies to be related to outcome did not show significant association with motor or cognitive decline in our study. A positive response to high volume LP has been considered a sign of reversibility of symptoms, which indicates that the patient is only in the first stages of deterioration ${ }^{24}$ and thus has a better chance of responding than do patients at later stages. In our study, however, motor outcome was not related to LP-induced improvement. Response to LP was also not significantly related to surgery outcome, which disagrees with studies that suggest that it is a good predictor of shunt outcome ${ }^{24,25}$. In this respect, our results could have been biased by the common practice in our department not to propose shunt surgery to patients who did not respond to LP. In fact, only one patient proposed for shunt surgery had a negative LP result.

The relevance of increased CSF stroke volume to NPH assessment is controversial. Preliminary studies suggest that hyperdinamic aqueductal flow is indicative of the reversibility of symptoms after shunt ${ }^{12}$. This relationship, however, was not observed consistently in subsequent studies ${ }^{26}$, and is not supported by our data.

Other clinical variables found by some investigators to predict outcome include gait dysfunction as the primary symptom of the triad ${ }^{21}$, presence of the complete triad ${ }^{15}$, and duration of symptoms ${ }^{27-29}$. This was not the case in our study, although duration was related to gait outcome in operated patients at trend level. Specific gait symptoms were not related to the outcome, which disagrees with the suggestion that the presence of frontal release signs represents worse post-shunt prognosis, made by our group in a previous study ${ }^{30}$.

\section{Limitations}

This study's main limitation is that the time between assessments (from T0 to T1) is different between patients. However, we should say that this variable was included in the data analysis, and did not appear to have a relevant influence on outcome. Also, the relatively small number of patients did not allow the use of statistics more powerful than chi-square, which does not permit multivariate analysis. Finally, patients were subjected to different surgical procedures (ventriculostomy, ventriculo-peritoneal shunt, etc), which could have biased outcome results.

\section{References}

1. Hakim S, Adams RD. The special clinical problem of symptomatic hydrocephalus with normal cerebrospinal fluid pressure. Observations on cerebrospinal fluid hydrodynamics. J Neurol Sci 1965;2:307-372.

2. Marmarou A, Bergsneider M, Klinge P, Relkin N, Black PM. The value of supplemental prognostic tests for the preoperative assessment of idiopathic normal-pressure hydrocephalus. Neurosurgery 2005;57(Suppl 3):S17-S28

3. Damasceno BP, Carelli EF, Honorato DC, Facure JJ. The predictive value of cerebrospinal fluid tap-test in normal pressure hydrocephalus. Arq Neuropsiquiatr 1997;55:179-185.
4. Delwel EJ, de Jong DA, Avezaat CJJ. The prognostic value of clinical characteristics and parameters of cerebrospinal fluid hydrodynamics in shunting for idiopathic normal pressure hydrocephalus. Acta Neurochirurgica (Wien) 2005;147:1037-1043.

5. Boon A, Tans J, Delwel EJ, Egeler-Peerdeman, Hanlo PW, Wurzer H, Hermans J. The Dutch Normal-Pressure Hydrocephalus Study - How to select patients for shunting? An analysis of four diagnostic criteria. Surg Neurol 2000;53:201-207.

6. Snijders AK, van de Warrenburg BP, Giladi N, Bloem BR. Neurological gait disorders in elderly people: clinical approach and classification. Lancet Neurol 2007; 6:63-74. 
7. Relkin N, Marmarou A, Klinge P, Bergsneider M, Black PM. Diagnosing Idopathic normal pressure hydrocephalus. Neurosurgery 2005;57(Suppl 3):S4-S16.

8. Folstein MF, Folstein SE, McHugh PR. Mini-Mental State. A practical method for grading the cognitive state of patients for the clinician. J Psychiatr Res 1975;12:189-198.

9. Morgado J, Rocha CS, Maruta C, Guerreiro M, Martins IP. Novos valores normativos do Mini-Mental State Examination. Sinapse 2009;9:10-16.

10. Pastor MA, Day BL, Marsden CD. Vestibular induced postural responses in Parkinson's disease. Brain 1993;116:1177-1190.

11. Jankovic J, Nutt JG, Sudarsky L. Classification, diagnosis and etiology of gait disorders. Adv Neurol 2001;87:119-133.

12. Bradley WG Jr, Scalzo D, Queralt J, et al. Normal-pressure hydrocephalus: evaluation with cerebrospinal fluid flow measurements at MR imaging. Radiology 1996;198:523-529.

13. American Psychiatric Association. Diagnostic and statistical manual of mental disorders. 4th ed. Washington DC: APA, 1994.

14. Kahlon B, Sjunnesson J, Rehncrona S. Long-term outcome in patients with suspected normal pressure hydrocephalus. Neurosurgery 2007;60:327-332

15. Poca MA, Mataró M, Del Mar Matarín M, Arikan F, Junqué C, Sahuquillo J. Is the placement of shunts in patients with idiopathic normalpressure hydrocephalus worth the risk? Results of a study based on continuous monitoring of intracranial pressure. $J$ Neurosurgery 2004;100:855-866.

16. Bugalho P, Alves L. Normal-pressure hydrocephalus: white matter lesions correlate negatively with gait improvement after lumbar puncture. Clin Neurol Neurosurg 2007;109:774-778.

17. Boon AJW, Tans JTJ, Delwel EJ et al. Dutch normal-pressure hydrocephalus study: the role of cerebrovascular disease. J Neurosurgery 1999;90:221-226.

18. Tullberg M, Jensaen C, Ekholm S, Wikkelso C. Normal pressure hydrocephalus: vascular white matter changes on MR images must not exclude patients from shunt surgery. American Journal of Neuroradiology 2001;22:1665-1673.

19. Viana-Baptista M, Bugalho P, Jordão C, et al. Cognitive function correlates with frontal white matter apparent diffusion coefficients in patients with leukoaraiosis. J Neurol 2008;255:360-366.
20. Krauss JK, Regel JP, Vach W, Droste DW, Borremans JJ, Mergner T. Vascular risk factors and arteriosclerotic disease in idiopathic normal-pressure hydrocephalus of the elderly. Stroke 1996;27:24-29

21. McGirt MJ, Woodworth G, Coon AL, Thomas G, Williams MA, Rigamonti D. Diagnosis, treatment, and analysis of long-term outcomes in idiopathic normal-pressure hydrocephalus. Neurosurgery 2008;62(Suppl 2):S670-S677.

22. Savolainen S, Hurskainen H, Paljärvi L, Alafuzoff I, Vapalahti M. Fiveyear outcome of normal pressure hydrocephalus with or without a shunt: predictive value of the clinical signs, neuropsychological evaluation and infusion test. Acta Neurochirurgica (Wien) 2002;144:515-523.

23. Savolainen S, Paljärvi L, Vapalahti M. Prevalence of Alzheimer's disease in patients investigated for presumed normal pressure hydrocephalus: a clinical and neuropathological study. Acta Neurochirurgica (Wien) 1999;141:849-853.

24. Wikkelso C, Andersson H, Blomstrand C, Lindqvist G. The clinical effect of lumbar puncture in normal pressure hydrocephalus.J Neurol Neurosurg Psychiatry 1982;45:64-69.

25. Kahlon B, Sundbarg G, Rehncrona S. Comparison between the lumbar infusion and CSF tap tests to predict outcome after shunt surgery in suspected normal pressure hydrocephalus. J Neurol Neurosurg Psychiatry 2002;73:721-726.

26. Kahlon B, Annertz M, Ståhlberg F, Rehncrona S. Is aqueductal stroke volume, measured with cine phase-contrast magnetic resonance imaging scans useful in predicting outcome of shunt surgery in suspected normal pressure hydrocephalus? Neurosurgery 2007;60:124-129

27. Kiefer M, Eymann R, Steudel WI. Outcome predictors for normal-pressure hydrocephalus. Acta Neurochirurgica 2006;96(Suppl):S364-S367.

28. Meier U, Lemcke J, Neumann U. Predictors of outcome in patients with normal-pressure hydrocephalus. Acta Neurochirurgica 2006;96(Suppl):S352-S357.

29. Meier U, Miethke C. Predictors of outcome in patients with normalpressure hydrocephalus. J Clin Neurosci 2003;10:453-459.

30. Bugalho P, Guimarães J. Gait disturbance in normal pressure hydrocephalus: a clinical study. Parkinson Relat Disord 2007;13:434-437. 